\title{
Wedge Resection of Tumor Before Lobectomy for Lung Cancer Could Be a No-touch Isolation Technique
}

\author{
MOTOAKI YASUKAWA, NORIYOSHI SAWABATA, TAKESHI KAWAGUCHI and SHIGEKI TANIGUCHI
}

Department of Thoracic and Cardiovascular Surgery, Nara Medical University School of Medicine, Nara, Japan

\begin{abstract}
Background/Aim: Circulating tumor cells (CTCs) can be a surrogate biomarker of prospective prognosis. Surgical manipulation can promote the dissemination of CTCs. Prognosis improvement is expected with the no-touch isolation technique (NTIT), preventing surgical manipulation. The Wedge resection of the tumor site before lobectomy could prevent surgical manipulation during lobectomy for nonsmall cell lung cancer (NSCLC) and reduce the shedding of tumor cells, similar to a NTIT. This study aimed to evaluate the effect of wedge resection technique. Patients and Methods: A total of 624 resected NSCLC patients were retrospectively analyzed. Patients were divided in two groups: Wedge and Non-Wedge. Overall survival (OS) curves were plotted using the Kaplan-Meier method. Results: The 5-year OS rates were $89.9 \%$ and $84.0 \%$ in the Wedge and NonWedge groups, respectively ( $p=0.033)$. Conclusion: The OS in the Wedge group was significantly better than that in the Non-Wedge group. Wedge resection technique for NSCLC may be a NTIT.
\end{abstract}

Surgery is the preferred treatment for non-small cell lung carcinoma (NSCLC) patients. After curative resection, approximately $50 \%$ of patients may develop local recurrence or distant metastases within 3 years (1).

Recently, some studies demonstrated that the presence of circulating tumor cells (CTCs) in the peripheral blood can be a surrogate biomarker of prospective recurrence and prognosis $(2,3)$. CTCs are released from the primary tumor into the bloodstream and have the potential to spread to distant sites

This article is freely accessible online.

Correspondence to: Motoaki Yasukawa, Department of Thoracic and Cardiovascular Surgery, Nara Medical University School of Medicine, 840 Shijyo-cho, Kashihara, Nara, 634-8522, Japan. Tel: +81 744223051, Fax: +81 744248040, e-mail: myasukawa@ naramedu.ac.jp

Key Words: Non-small cell lung carcinoma, prognosis, no-touch isolation technique. and develop into micro-metastatic deposits (4). Furthermore, surgical manipulation could promote the dissemination of tumor cells into the circulation (5-7). Prognosis improvement is expected with the no-touch isolation technique (NTIT) due to preventing surgical manipulation. The NTIT reduces intraoperative shedding of tumor cells into the circulation in colorectal cancer $(8,9)$, hepatocellular carcinoma (10), gastrointestinal stromal tumor (GIST) (11), and pancreatic cancer (12). Another surgical technique that may prevent the dissemination of tumor cells into the bloodstream is to ligate the effluent veins first during surgery (13). Tumor cells can be detected in effluent venous blood during surgery (14). In addition, vascular invasion within the tumor is common in lung cancer, which might be responsible for the high incidence of hematogenous spread of tumor cells (15). Although it is controversial whether the pulmonary vein (PV) should be ligated first, Wei et al. (16) demonstrated that the PV-first group had significantly better outcomes than the pulmonary artery (PA)-first group in terms of 5-year survival, recurrencefree survival, and lung cancer-specific survival. Furthermore, they demonstrated that the PA-first procedure was an independent risk factor for the increase in the number of CTCs during surgery in multivariate analysis.

However, it is not possible to ligate the PV without the following surgical manipulations: dissection of the tissue around the PV that occurs around and away from the lung. This procedure can squeeze tumor cells from the tumor site, and the tumor cells can then circulate throughout the bloodstream. On the other hand, pulmonary wedge resection of the tumor site before lobectomy may be superior to reduce the number of CTCs to the PV-first ligation method during lobectomy for NSCLC. Wedge resection may be considered one of NTITs. The advantage of wedge resection of the tumor site before lobectomy is that the absence of the tumor could prevent release of tumor cells that may occur during lobectomy for non-small cell lung cancer. Unfortunately, there have never been the study of the relation between wedge resection during lobectomy for NSCLC and no-touch isolation techniques.

We hypothesized is that the overall survival and recurrence-free survival will be improved for wedge 
Table I. Clinicopathological characteristics of patients.

\begin{tabular}{|c|c|c|c|}
\hline & Wedge $(n=256)$ & Non-Wedge $(n=368)$ & $p$-Value \\
\hline Age $<70 / \geq 70$ & $140 / 116$ & $167 / 201$ & $0.023^{*}$ \\
\hline Gender: Male/Female & $151 / 105$ & $240 / 128$ & 0.130 \\
\hline \multicolumn{4}{|l|}{ CT findings: } \\
\hline Pure GGN/Others & $52 / 224$ & $44 / 324$ & $0.005^{*}$ \\
\hline \multicolumn{4}{|l|}{ Location: } \\
\hline Peripheral/Others & $247 / 9$ & $242 / 126$ & $<0.001 *$ \\
\hline \multicolumn{4}{|l|}{ c-Stage } \\
\hline $\mathrm{Tmin} / \mathrm{T} 1 \mathrm{a} / \mathrm{T} 1 \mathrm{~b} / \mathrm{T} 1 \mathrm{c} / \mathrm{T} 2 \mathrm{a} / \mathrm{T} 2 \mathrm{~b} / \mathrm{T} 3$ or more & $2 / 62 / 101 / 62 / 24 / 5 / 0$ & $4 / 23 / 73 / 103 / 93 / 40 / 32$ & 0.098 \\
\hline \multicolumn{4}{|l|}{ p-Stage } \\
\hline $\mathrm{Tmin} / \mathrm{T} 1 \mathrm{a} / \mathrm{T} 1 \mathrm{~b} / \mathrm{T} 1 \mathrm{c} / \mathrm{T} 2 \mathrm{a} / \mathrm{T} 2 \mathrm{~b} / \mathrm{T} 3$ or more & $8 / 24 / 93 / 58 / 62 / 3 / 8$ & $5 / 10 / 68 / 85 / 108 / 45 / 37$ & 0.098 \\
\hline Invasive size of the tumor $(\mathrm{cm})$ & 2.08 & 3.23 & \\
\hline$<3 />3$ & $224 / 32$ & $198 / 170$ & $<0.001 *$ \\
\hline $\mathrm{p}-\mathrm{N} 0 / \mathrm{N} 1 / \mathrm{N} 2$ or more & $224 / 14 / 18$ & $284 / 53 / 31$ & $0.001 *$ \\
\hline \multicolumn{4}{|l|}{ Histology: } \\
\hline Ad & 200 & 249 & \\
\hline $\mathrm{Sq}$ & 39 & 77 & \\
\hline Others & 17 & 42 & $0.024^{*}$ \\
\hline $\mathrm{Pl}+/-$ & $55 / 201$ & $105 / 263$ & 0.051 \\
\hline $\mathrm{Ly}+/-$ & $88 / 168$ & $189 / 179$ & $<0.001 *$ \\
\hline$V+/-$ & $78 / 178$ & $184 / 184$ & $<0.001 *$ \\
\hline \multicolumn{4}{|l|}{ Preoperative CEA } \\
\hline$<5 />5 \mathrm{ng} / \mathrm{mL}$ & $195 / 61$ & $240 / 128$ & $0.003^{*}$ \\
\hline \multicolumn{4}{|l|}{ Period of days from point out to operation } \\
\hline$<90 />90$ & $120 / 79$ & $185 / 147$ & $<0.001 *$ \\
\hline Adjuvant therapy Yes/No & $66 / 190$ & $143 / 225$ & $<0.001 *$ \\
\hline Death & 20 & 52 & $0.016^{*}$ \\
\hline Recurrence & 35 & 128 & $<0.001 *$ \\
\hline
\end{tabular}

CT: Computed tomography; GGN: ground-glass nodule; c-Stage: clinical stage; p-Stage: pathological stage; p-N: pathological-N; Ad: adenocarcinoma; Sq: squamous cell carcinoma; Pl: pleural invasion; Ly: lymphatic invasion; V: vascular invasion; CEA; carcinoembryonic antigen.

resection compared to non-wedge resection before lobectomy for NSCLC patients. The aim of this study was to evaluate the effect of wedge resection of the tumor site before lobectomy as a no-touch isolation technique. This is the first study to investigate the efficacy of wedge resection during lobectomy for NSCLC.

\section{Patients and Methods}

Among 891 patients who underwent resection of NSCLC at the Nara Medical University Hospital between January 2010 and December 2016, 624 NSCLC patients who underwent complete resection (lobectomy) were selected and their medical records were reviewed. The clinical $\mathrm{T}$ descriptor was reclassified based on the TNM staging (eighth edition). Exclusion criteria included the presence of other concomitant malignant diseases and determination of NSCLC by intraoperative needle lung biopsy. The remaining 624 patients were divided into two groups: the group of patients who underwent wedge resection of the tumor site before lobectomy (Wedge group, $n=256$ ) and the group of patients who did not undergo wedge resection of the tumor site before lobectomy (NonWedge group, $\mathrm{n}=368$ ).

We used video-assisted thoracoscopic surgery technique to resect the lung cancers. This involved three incisions; a camera port was inserted in the anterior axillary line through the seventh or eighth intercostal space; a second 1-cm incision was made in the anterior axillary line through the fourth or fifth intercostal space, and a 4to $5-\mathrm{cm}$ working port was placed in the middle axillary line through the fourth or fifth intercostal space. The patients whose preoperative diagnosis was not yet decided underwent wedge resection when the location of the tumor could be partially resected without any difficulties. At this time, we were not committed to PV-first ligation during lobectomy. Instead, we prioritized ease of the lobectomy procedure regarding vessel ligation.

Follow-up examinations were symptom-oriented, but all patients underwent medical checkups and chest X-rays at least twice a year, and whole-body computed tomography (CT) was performed at least once a year. The observation period began on the day of operation and was terminated on December 31, 2018.

Either the Chi-square test or Fisher's exact test was used, as appropriate, to analyze any correlation between the two groups. Overall survival curves and recurrence-free survival curves were plotted using the Kaplan-Meier method, and the statistical significance of differences between groups was determined by the log-rank test. Univariate and multivariate Cox regression analyses were used to evaluate the hazard ratio with the endpoint of overall survival (period from the day of operation to the day of death) or recurrence-free survival. All $p$-values were two-sided, and $p$-values $<0.05$ were considered to indicate a statistically significant 


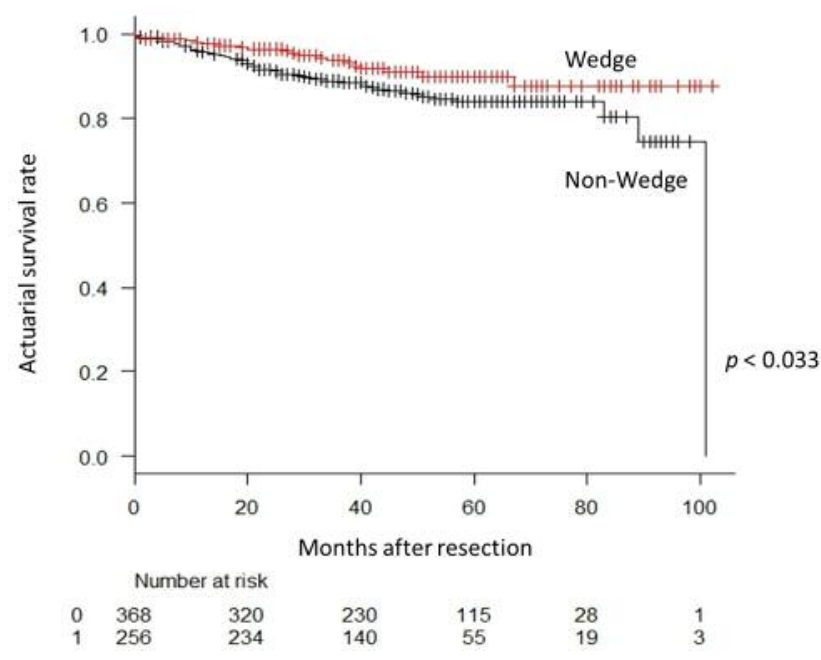

Figure 1. Overall survival curve for patients according to receipt of wedge resection before the lobectomy procedure. The 5-year overall survival rate is $89.9 \%$ in the Wedge group and $84.0 \%$ in the Non-Wedge group. The difference between the groups is statistically significant $(p=0.033)$.

difference. All analyses were conducted using EZR on R commander version 1.33 (Saitama, Japan).

This retrospective study was approved by our institute Ethics Review Board (No. 2263). The Ethics Review Board of our institute waived the requirement to obtain written informed consent from patients and approved the study protocol, because individual patients were not identified in this retrospective study.

\section{Results}

A total of 256 patients in the Wedge group and 368 patients in the Non-Wedge group were included in this study. The median follow-up period was 49 months (range 1-102 months). Table I shows the clinicopathological characteristics of patients in both groups. There were statistically significant differences in age, ground-glass nodule (GGN), location of the tumor, invasive size of the tumor, positivity of lymph node metastasis, pleural invasion, lympho-vascular involvement, administration of the adjuvant therapy, and high preoperative carcinoembryonic antigen (CEA), which were more frequently observed in patients in the Non-Wedge group than those in the Wedge group (Fisher's exact test).

During the observation period, NSCLC recurrence was identified in 35 patients in the Wedge group and 128 patients in the Non-Wedge group. Twenty patients in the Wedge group and 52 in the Non-Wedge group died during the observation period. The 5-year overall survival rates were $89.9 \%$ (95\% confidence interval $[\mathrm{CI}]=84.2-93.6)$ and $84.0 \%(95 \% \mathrm{CI}=79.2-87.8)$ in the Wedge and Non-Wedge groups, respectively $(p=0.033)$ (Figure $1)$. The 5-year recurrence-free survival rates were $81.8 \%(95 \%$

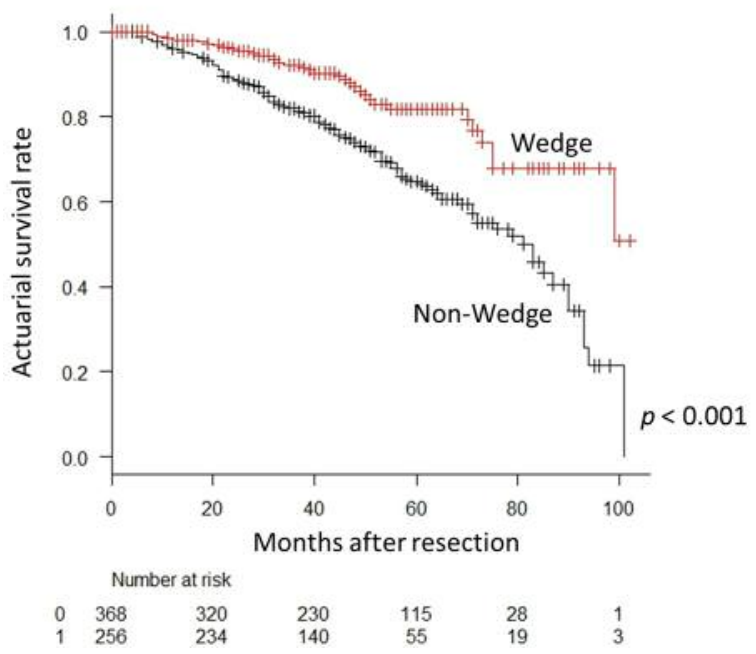

Figure 2. Recurrence-free survival curve for patients according to receipt of wedge resection before the lobectomy procedure. The 5-year recurrence-free survival rate is $81.8 \%$ in the Wedge group and $64.8 \%$ in the Non-Wedge group. The difference between the groups is statistically significant $(p<0.001)$.

$\mathrm{CI}=74.1-87.3)$ and $64.8 \%(95 \% \mathrm{CI}=58.8-70.1)$ in the Wedge and Non-Wedge groups, respectively $(p<0.001)$ (Figure 2$)$.

In the analysis of relative risk with the endpoint of overall survival, age, sex, wedge resection, the period from tumor discovery to operation, pure GGN on CT, histological type, pathological tumor infiltration diameter, $\mathrm{pT}$ stage, $\mathrm{pN}$ stage, pleural invasion (pl) factor, vascular invasion (v) factor, lymphatic invasion (ly) factor, and preoperative CEA were indicators of survival; however, in multivariate analysis, age, $\mathrm{pN}$ stage, and $\mathrm{v}$ factor were independent survival predictors (Tables II and III). In the analysis of relative risk with the endpoint of cancer recurrence, the same measures as for overall survival, except for age and sex, were indicators of recurrence, whereas in multivariate analysis, wedge resection, invasive size of the tumor, $\mathrm{pN}$ stage, and $\mathrm{v}$ factor were independent recurrence predictors (Tables IV and V).

\section{Discussion}

In this study, the overall survival and recurrence-free survival rates in the Wedge group were significantly better than those in the Non-Wedge group. Intraoperative wedge resection was shown to be one of the independent predictive factors of recurrence in NSCLC patients.

CTCs, originating from primary tumor sites, mobilize into the bloodstream as a result of intrinsic factors, such as active migration and invasion, or extrinsic factors, such as passive shedding by surgical manipulation, biopsy, and other iatrogenic sources (17). Numerous studies have demonstrated 
Table II. Univariate analysis of factors influencing survival of patients after complete resection of primary lung cancer.

\begin{tabular}{lccc}
\hline & Hazard ratio & $95 \%$ CI & $p$-Value \\
\hline Age $\geq 70$ & 1.965 & $1.206-3.203$ & $0.007^{*}$ \\
Gender: Male/Female & 2.457 & $1.389-4.345$ & $0.002^{*}$ \\
Wedge resection & 0.574 & $0.342-0.962$ & $0.035^{*}$ \\
Period of days from point & & & \\
out to operation $\geq 90$ & 0.394 & $0.232-0.667$ & $<0.001^{*}$ \\
CT findings: Pure GGN & 0.066 & $0.009-0.476$ & $0.007^{*}$ \\
Location: Peripheral & 1.058 & $0.606-1.848$ & 0.843 \\
Histology: & & & \\
$\quad$ Sq/Non-Sq & 2.164 & $1.300-3.604$ & $0.017^{*}$ \\
$\quad$ Ad/Non-Ad & 0.402 & $0.253-0.641$ & $<0.001^{*}$ \\
Invasive size of the tumor & 3.440 & $2.150-5.506$ & $<0.001^{*}$ \\
>3 cm & & & \\
p-T2 or more/T1 or less & 4.948 & $3.064-7.990$ & $<0.001^{*}$ \\
p-N1 or more/N0 & 2.149 & $1.612-2.866$ & $<0.001^{*}$ \\
Pl+ & 3.518 & $2.211-5.599$ & $<0.001^{*}$ \\
V+ & 6.292 & $3.560-11.120$ & $<0.001^{*}$ \\
Ly+ & 4.799 & $2.752-8.367$ & $<0.001^{*}$ \\
Adjuvant therapy: Yes & 2.178 & $1.371-3.459$ & $<0.001^{*}$ \\
Preoperative CEA $\geq 5 \mathrm{ng} / \mathrm{mL}$ & 2.470 & $1.550-3.936$ & $<0.001^{*}$ \\
\hline
\end{tabular}

CI: Confidence interval; CT: computed tomography; GGN: ground-glass nodule; Sq: squamous cell carcinoma; p-T: pathological-T; p-N: pathological-N; Ad: adenocarcinoma; Pl: pleural invasion; V: vascular invasion; Ly: lymphatic invasion; CEA; carcinoembryonic antigen.

that surgical manipulation can promote the dissemination of tumor cells into the circulation (5-7).

It is important to prevent increased numbers of CTCs that may shed from the primary tumor due to surgical intervention for NSCLC. Interestingly, even for early stage lung cancer, CTCs can be detected in $60-80 \%$ in patients $(18,19)$. Recently, Murlidhar et al. (20) reported that PV had significantly not only higher number of CTCs, but also larger CTC clusters compared to pre-operative and intra-operative peripheral vein among early stage lung cancer patients. Duan et al. (17) demonstrated that CTC counts after lobectomy for lung cancer were significantly higher than those before PV interruption. These results suggested that surgical manipulation may dislodge tumor cells into the PV, because the pulmonary vein is an overflow channel for tumor cell metastasis. Surgical manipulations may squeeze the tumor and further promote the spread of tumor cells into circulation (7).

The NTIT intraoperative shedding of tumor cells into the circulation from solid cancer (8-12). In addition, another surgical technique that may prevent the dissemination of tumor cells into the bloodstream involves ligating the effluent veins first during surgery (13). Tumor cells can be detected in effluent venous blood during surgery (14). Furthermore, vascular invasion within the tumor is common in lung cancer (15).

Although previous studies demonstrated that intraoperative manipulation increases the number of CTCs that shed into the
Table III. Multivariate analysis of factors influencing survival of patients after complete resection of primary lung cancer.

\begin{tabular}{lccl}
\hline & Hazard ratio & $95 \%$ CI & $p$-Value \\
\hline Age $\geq 70$ & 1.906 & $1.166-3.117$ & $0.010^{*}$ \\
Wedge resection & 0.848 & $0.501-1.434$ & 0.537 \\
CT findings: Pure GGN & 0.234 & $0.031-1.794$ & 0.162 \\
p-T2 or more/T1 or less & 1.726 & $0.969-3.074$ & 0.064 \\
p-N1 or more/N0 & 1.562 & $1.128-2.165$ & $0.007^{*}$ \\
V+ & 2.989 & $1.365-6.548$ & $0.006^{*}$ \\
Ly+ & 1.215 & $0.562-2.626$ & 0.621 \\
\hline
\end{tabular}

CI: Confidence interval; CT: computed tomography; GGN: ground-glass nodule; p-T: pathological-T; p-N: pathological-N; V: vascular invasion; Ly: lymphatic invasion; CEA: carcinoembryonic antigen.

blood of patients with NSCLC, whether the drainage PV should be ligated first remains controversial (21). Hashimoto et al. (7) reported that the increased PV CTC count prior and subsequent to surgical manipulation for lobectomy was not significantly associated with the sequence of vessel interruption. Refaely et al. (22) also demonstrated that that the sequence of vessel interruption was not a risk factor for recurrence. He et al. (23) reported that the sequence of pulmonary vessel ligation during video-assisted thoracoscopic surgery lobectomy for NSCLC had no significant effects on overall survival and recurrence-free survival. Therefore, ligating the PA-first remains an option during lobectomy based on the preference of the surgeon or the minimally invasive surgery technique used, particularly for upper lobectomy (21).

Recently, Wei et al. (16) demonstrated that the PV-first group had a significantly better outcome than the PA-first group in terms of 5-year survival, disease-free survival, and lung cancer-specific survival. Furthermore, they demonstrated that the PA-first procedure was an independent risk factor for the increase of CTCs during surgery in multivariate analysis. Hashimoto et al. (24) reported that increasing CTCs in the PV during surgical manipulation was significantly correlated with postoperative distant metastasis in completely resected NSCLC patients, although neither recurrence-free survival nor overall survival was significantly correlated with the increase in CTCs in PV. Furthermore, Song et al. (25) conducted a prospective randomized study related to the invasiveness and adhesiveness of malignant tumor cells and suggested that ligation of the PV should be performed first during lobectomy. Surgical manipulation itself may stimulate the occurrence of blood micro-metastases. Ligation of the PV first during surgery may help prevent blood micrometastases.

PV-first ligation should be good for the prognosis of surgically resected NSCLC patients. However, in the real world, the PV cannot be ligated immediately at the start of 
Table IV. Univariate analysis of factors influencing recurrence for patients after complete resection of primary lung cancer.

\begin{tabular}{lccc}
\hline & Hazard ratio & $95 \%$ CI & $p$-Value \\
\hline Age $\geq 70$ & 1.293 & $0.948-1.763$ & 0.105 \\
Gender: Male/Female & 1.370 & $0.988-1.900$ & 0.059 \\
Wedge resection & 0.430 & $0.295-0.626$ & $<0.001^{*}$ \\
Period of days from point & & & \\
out to operation $\geq 90$ & 0.490 & $0.347-0.690$ & $<0.001^{*}$ \\
CT findings: Pure GGN & 0.149 & $0.061-0.362$ & $<0.001^{*}$ \\
Location: Peripheral & 0.862 & $0.611-1.218$ & 0.400 \\
Histology: & & & \\
$\quad$ Sq/Non-Sq & 1.352 & $0.918-1.992$ & 0.127 \\
$\quad$ Ad/Non-Ad & 0.640 & $0.462-0.885$ & $0.007^{*}$ \\
Invasive size of the tumor & 3.188 & $2.340-4.344$ & $<0.001^{*}$ \\
$>3$ cm & & & \\
p-T2 or more/T1 or less & 3.796 & $2.697-5.342$ & $<0.001^{*}$ \\
p-N1 or more/N0 & 2.732 & $2.290-3.259$ & $<0.001^{*}$ \\
P1+ & 2.749 & $2.015-3.751$ & $<0.001^{*}$ \\
V+ & 4.373 & $3.115-6.141$ & $<0.001^{*}$ \\
Ly+ & 5.327 & $3.634-7.810$ & $<0.001^{*}$ \\
Adjuvant therapy: Yes & 2.925 & $2.140-3.999$ & $<0.001^{*}$ \\
Preoperative CEA $\geq 5$ ng/ml & 2.336 & $1.715-3.184$ & $<0.001^{*}$ \\
\hline
\end{tabular}

CI: Confidence interval; CT: computed tomography; GGN: ground-glass nodule; Sq: squamous cell carcinoma; Ad: adenocarcinoma; $\mathrm{p}-\mathrm{T}$ : pathological-T; p-N: Pathological-N; Pl: pleural invasion; V: vascular invasion; Ly: lymphatic invasion; CEA; carcinoembryonic antigen.

lobectomy before the shedding of tumor cells occurs due to surgical manipulations such as dissection of tissues and moving or turning over the lung. Before the PV is ligated from the lung during lobectomy, careful dissection of tissues around the PV and softly moving the lung could disturb the tumor site and squeeze the tumor cells out from the tumor. Even bronchoscopic biopsy can increase the count of PV CTCs before the procedure $(17,26)$.

During lung cancer surgery, one could hypothesize that CTCs could be dislodged by surgical manipulation; therefore, preventing the shedding of tumor cells would reduce the seeding of cancer cells, resulting in decreased metastatic spread.

We, therefore, hypothesized that the overall survival and recurrence-free survival is improved for wedge resection compared with non-wedge resection before lobectomy for NSCLC patients. The wedge resection technique could prevent surgical manipulation during lobectomy for NSCLC, and reduce the shedding of tumor cells, similar to the notouch isolation technique for lobectomy. Our findings show that wedge resection was significantly better for patients undergoing surgical resection for lung cancer. This is the first study to show that wedge resection has the efficacy to reduce recurrence of NSCLC. This efficacy may be related to the reduction in the number of CTCs that are related to surgical manipulation.
Table V. Multivariate analysis of factors influencing recurrence of patients after complete resection of primary lung cancer.

\begin{tabular}{lccc}
\hline & Hazard ratio & $95 \%$ CI & $p$-Value \\
\hline Gender: Male/Female & 0.782 & $0.782-1.597$ & 0.543 \\
Wedge resection & 0.498 & $0.326-0.761$ & $0.001^{*}$ \\
CT findings: Pure GGN & 0.882 & $0.326-2.383$ & 0.804 \\
Histology: & & & \\
$\quad$ Ad / Non-Ad & 1.200 & $0.823-1.751$ & 0.343 \\
Invasive size of the tumor & 1.610 & $1.120-2.315$ & $0.010^{*}$ \\
>3 cm & & & \\
p-N1 or more / N0 & 2.079 & $1.666-2.594$ & $<0.001^{*}$ \\
Pl+ & 1.027 & $0.724-1.458$ & 0.880 \\
V+ & 1.672 & $1.053-2.654$ & $0.029 *$ \\
Ly+ & 1.367 & $0.800-2.337$ & 0.253 \\
Preoperative CEA $>5 \mathrm{ng} / \mathrm{mL}$ & 1.209 & $0.871-1.679$ & 0.258 \\
\hline
\end{tabular}

CI: Confidence interval; CT: computed tomography; GGN: ground-glass nodule; Ad: adenocarcinoma; p-N: pathological-N; Pl: pleural invasion; V: vascular invasion; Ly: lymphatic invasion; CEA; carcinoembryonic antigen.

At our institution, wedge resection is performed using ring-shaped forceps. The ring-shaped forceps are locked and not released until completion of the wedge resection. Previously, we demonstrated that patients who underwent pulmonary wedge resection of lung cancer had a reduced probability of CTC detection after surgery when ring-shaped forceps were used without tumor release (27). Ring-shaped forceps generate high pressure by compression, which can reduce the risk of tumor cell spreading, therefore; wedge resection may be considered a no-touch isolation technique.

The wedge resection method is easy and can be performed immediately when beginning the surgical procedure. Despite needing several cartridges of staples, the wedge resection method results in improved oncological outcomes due to the reduction of intraoperative shedding of tumor cells into the circulation.

The limitations of this study include the retrospective design and single-institution setting. Also, there were significant differences between the two groups for clinicopathological characteristics. We might consider matched analysis for the two groups, because they were not matched in terms of loco-regional invasiveness, which could create a bias in outcome analysis. However, the patients whose tumor site could be partially resected without any difficulties tend to be in small NSCLC. We used multivariate analysis in this study. More research is needed to investigate the correlation between CTC detection and poor prognosis, and between wedge resection and CTC detection. CTC detection for NSCLC might be a difficult and complicated technique because of a lack of standard isolation methods, and heterogeneity of CTCs. However, recent research studies have reported the development of the following techniques 
for tumor cell detection: liquid biopsy, analysis of circulating biomarkers from peripheral blood, such as CTCs, and circulating tumor DNA (ctDNA) $(28,29)$. The analysis of ctDNA might be a key to the solution of tumor heterogeneity. A prospective study, such as the analysis of CTC between Wedge group and Non-Wedge group pre-and post-operatively, is recommended to obtain more accurate evidence.

In conclusion, this is the first report to reveal the efficacy of wedge resection before lobectomy for NSCLC patients. The overall survival and recurrence-free survival in the Wedge group were significantly better than in patients of the Non-Wedge group, and intraoperative wedge resection was shown to be one of the independent predictive factors of recurrence in NSCLC patients. Our data support the idea that wedge resection before lobectomy for NSCLC patients may be considered a NTIT. This observation is helpful to improve the surgical intervention strategy and outcomes for patients with NSCLC.

\section{Conflicts of Interest}

The Authors declare that they have no conflict of interest regarding this study.

\section{Author Contributions}

Study concept and design: M.Y. Drafting of the manuscript: M.Y. Critical revision of the manuscript: N.S. and T.K. Study supervision: S.T.

\section{References}

1 Shinohara S, Otsuki R, Onitsuka T, Machida K, Matsuo M, Nakagawa $M$ and Sugaya $M$ : Postoperative C-reactive protein is a predictive biomarker for survival after non-small cell lung cancer resection. Anticancer Res 39(4): 2193-2198, 2019. PMID: 30952767. DOI: 10.21873/anticanres.13334

2 Kuboki Y, Matsusaka S, Minowa S, Shibata H, Suenaga M, Shinozaki E, Mizunuma N, Ueno M, Yamaguchi T and Hatake K: Circulating tumor cell (CTC) count and epithelial growth factor receptor expression on CTCs as biomarkers for cetuximab efficacy in advanced colorectal cancer. Anticancer Res 33(9), 3905-3910, 2013. PMID: 24023327.

3 Tognela A, Spring KJ, Becker T, Caixeiro NJ, Bray VJ, Yip PY, Chua W, Lim SH and de Souza P: Predictive and prognostic value of circulating tumor cell detection in lung cancer: a clinician's perspective. Crit Rev Oncol Hematol 93(2): 90-102, 2015. PMID: 25459665. DOI: 10.1016/j.critrevonc.2014.10.001

4 Tayoun T, Faugeroux V, Oulhen M, Aberlenc A, pawlikowska P and Farace F: CTC-derived models: A window into the seeding capacity of circulating tumor cells (CTCs). Cells 8(10): pii: E1145, 2019. PMID: 31557946. DOI: 10.3390/cells8101145

5 Weitz J and Herfarth C: Surgical strategies and minimal residual disease detection. Semin Surg Oncol 20(4): 329-333, 2001. PMID: 11747275. DOI: 10.1002/ssu.1051

6 Tsumura H, Satoh T, Ishiyama H, Tabata KI, Takenaka K, Sekiguchi A, Nkamura M, Kitano M, Hayakawa K and Iwamura
M: Perioperative search for circulating tumor cells in patients undergoing prostate brachytherapy for clinically nonmetastatic prostate cancer. Int J Mol Sci 18(1): pii:E128, 2017. PMID: 28085051. DOI: $10.3390 /$ ijms 18010128

7 Hashimoto M, Tanaka F, Yoneda K, Takuwa T, Matsumoto S, Okumura Y, KondoN, Tsubota N, Tsujimura T, Tabata C, Nakano $\mathrm{T}$ and Hasegawa S: Significant increase in circulating tumour cells in pulmonary venous blood during surgical manipulation in patients with primary lung cancer. Interact Cardiovasc Thorac Surg 18(6): 775-783, 2014. PMID: 24618055. DOI: 10.1093/icvts/ivu048

8 Turnbull RB Jr, Kyle K, Watson FR and Spratt J: Cancer of the colon: the influence of the no-touch isolation technic on survival rates. CA Cancer J Clin 18(2): 82-87, 1969. PMID: 4967700. DOI: $10.3322 /$ canjclin.18.2.82

9 Sales JP, Wind P, Douard R, Cugnenc PH and Loric S: Blood dissemination of colonic epithelial cells during no-touch surgery for rectosigmoid cancer. Lancet 354(9176): 392, 1999. PMID: 10437871. DOI: 10.1016/S0140-6736(99)92164-5

10 Liu CL, Fan ST, Cheung ST, Lo CM, Ng IO and Wong J: Anterior approach versus conventional approach right hepatic resection for large hepatocellular carcinoma: a prospective randomized controlled study. Ann Surg 244(2): 194-203, 2006. PMID: 16858181. DOI: 10.1097/01.sla.0000225095.18754.45

11 Kiyozaki H, Saito M, Chiba H, Takata O and Rikiyama T: Laparoscopic wedge resection of the stomach for gastrointestinal stromal tumor (GIST): non-touch lesion lifting method. Gastric Cancer 17(2): 337-340, 2014. PMID: 23743878. DOI: $10.1007 / \mathrm{s} 10120-013-0272-8$

12 Gall TM, Jacob J, Frampton AE, Krell J, Kyriakides C, Castellano L, Stebbing J and Jiao LR: Reduced dissemination of circulating tumor cells with no-touch isolation surgical technique in patients with pancreatic cancer. JAMA Surg 149(5): 482-485, 2014. PMID: 24599353. DOI: 10.1001/jamasurg.2013.3643

13 Kurusu Y, Yamashita J, Hayashi N, Mita S, Fujino N and Ogawa $\mathrm{M}$ : The sequence of vessel ligation affects tumor release into the circulation. J Thorac Cardiovasc Surg 116(1): 107-113, 1998. PMID: 9671904. DOI: 10.1016/s0022-5223(98)70248-X

14 McCulloch P, Choy A and Martin L: Association between tumour angiogenesis and tumour cell shedding into effluent venous blood during breast cancer surgery. Lancet 346(8986): 1334-1335, 1995. PMID: 7475773. DOI: 10.1016/s01406736(95)92345-4

15 Bodendorf MO, Haas V, Laberke HG, Blumenstock G, Wex P and Graeter T: Prognostic value and therapeutic consequences of vascular invasion in non-small cell lung carcinoma. Lung Cancer 64(1): 71-78, 2009. PMID: 18790545. DOI: 10.1016/ j.lingcan.2008.07.011

16 Wei S, Guo C, He J, Tan Q, Mei J, Yang Z, Liu C, Pu Q, Ma L, Yuan Y, Lin F, Zhu Y, Liao H, Wang W, Liu Z, Li Q, Jiang B, Li C, Xia L, Zhao K, Gan F, Cheng J, Wu Z, Wang Y, Lin Y, Kou Y, Che G, Chen L, Li J and Liu J: Effect of vein-first vs artery-first surgical technique on circulating tumor cells and survival in patients with non-small cell lung cancer. A randomized clinical trial and registry-based propensity score matching analysis. JAMA Surg 154(7): e190972, 2019. PMID: 31042283. DOI: 10.1001/jamasurg.2019.0972

17 Duan X, Zhu Y, Cui Y, Yang Z, Zhou S,Han Y, Yu D, Xiao N, Cao X, Li Y, Liu S, Wang Z, Zhang W, Feng L, Zhang K, Shou J, Liu $\mathrm{Z}$ and $\mathrm{Xu} \mathrm{S}$ : Circulating tumor cells in the pulmonary vein increase significantly after lobectomy: A prospective observational 
study. Thoracic Cancer 10(2): 163-169, 2019. PMID: 30511800. DOI: $10.1111 / 1759-7714.12925$

18 Li Y, Tian X, Gao L, Jiang X, Fu R, Zhang T, Ren T, Hu P, Wu $\mathrm{Y}$, Zhao $\mathrm{P}$ and Yang D: Clinical significance of circulating tumor cells and tumor markers in the diagnosis of lung cancer. Cancer Med 8(8): 3782-3792, 2019. PMID: 31132233. DOI: 10.1002/ cam4.2286

19 Chudasama D, Barr J, Beeson J, Beddow E, McGonigle N, Rice A, Nicholson A and Anikin V: Detection of circulating tumour cells and survival of patients with non-small cell lung cancer. Anticancer Res 37(1): 169-174, 2017. PMID: 28011487. DOI: 10.21873/anticanres.11302

20 Murlidhar V, Reddy RM, Fouladdel S, Zhao L, Ishikawa MK, Grabauskiene S, Zhang Z, Lin J, Chang AC, Carrott P, Lynch WR, Orringer MB, Kumar-Sinha C, Palanisamy N, Beer DG, Wicha MS, Ramnath N, Azizi E and Nagrath S: Poor prognosis indicated by venous circulating tumor cell clusters in early-stage lung cancers. Cancer Res 77(18): 5194-5206, 2017. PMID: 28716896. DOI: 10.1158/0008-5472.CAN-162072

21 LV C, Zhao B, Wang L, Zhang P, Ma Y, Wang Y, Wu N, Wu Y and Yang Y: Detection of circulating tumor cells in pulmonary venous blood for resectable non-small cell lung cancer. Oncol Lett 15(1): 1103-1112, 2018. PMID: 29422972. DOI: 10.3892/ ol.2017.7405

22 Refaely Y, Sadetzki S, Chetrit A, Simansky DA, Paley M, Modan B and Yellin A: The sequence of vessel interruption during lobectomy for non-small cell lung cancer: Is it indeed important? J Thorac Cardiovasc Surg 125(6): 1313-1320, 2003. PMID: 12830050. DOI: 10.10016/s0022-5223(03)00022-9

$23 \mathrm{He} \mathrm{HH}$, He JX, Hao ZX, Wang W and He JX: Association between different sequences of vessel ligation during videoassisted thoracoscopic lobectomy and survival in patients with non-small cell lung cancer. J Thorac Dis 11(3): 686-693, 2019. PMID: 31019755. DOI: 10.21037/jtd.2019.02.69

24 Hashimoto M, Tanaka F, Yoneda K, Takuwa T, Matsumoto S, Okumura Y, Kondo N, Tsujimura T, Nakano T and Hasegawa S: Positive correlation between postoperative tumor recurrence and changes in circulating tumor cell counts in pulmonary venous blood (pvCTC) during surgical manipulation in non-small cell lung cancer. J Thorac Dis 10(1): 298-306, 2018. PMID: 29600060. DOI: $10.21037 /$ jtd.2017.12.56
25 Song PP, Zhang W, Zhang B, Liu Q and Du J: Effects of different sequences of pulmonary artery and vein ligations during pulmonary lobectomy on blood micrometastasis of nonsmall cell lung cancer. Oncol Lett 5(2): 463-468, 2013. PMID: 23420582. DOI: $10.3892 /$ ol.2012.1022

26 Reddy RM, Murlidhar V, Zhao L, Grabauskiene S, Zhang Z, Ramnath N, Lin J, Chang AC, Carrott P, Lynch W, Orringer MB, Beer DG and Nagrath S: Pulmonary venous blood sampling significantly increases the yield of circulating tumor cells in early-stage lung cancer. J Thorac Cardiovasc Surg 151(3): 852858, 2016. PMID: 26614417. DOI: 10.1016/j.jtcvs.2015.09.126

27 Sawabata N, Hyakutaka T, Kawaguchi T, Yasukawa M, Kawai $\mathrm{N}$, Tojo T and Taniguchi S: A no-touch technique for pulmonary wedge resection of lung cancer. Gen Thorac Cardiovasc Surg 66(3): 161-167, 2018. PMID: 29128899. DOI: 10.1007/s11748017-0863-0

28 Lim M, Kim CJ, Sunkara V, Kim MH and Cho YK: Liquid biopsy in lung cancer: clinical aapplications of circulating biomarker (CTCs and ctDNA). Micromachines (Basal) 9(3): E100, 2018. PMID: 30424034. DOI: 10.3390/mi9030100

$29 \mathrm{Wu}$ Z, Yang Z, Dai Y, Zhu Q and Chen LA: Update on liquid biopsy in clinical management of non-small cell lung cancer. Onco Targets Ther 12: 5097-5109, 2019. PMID: 31303765. DOI: 10.2147/OTT.S203070
Received November 24, 2019

Revised December 5, 2019

Accepted December 10, 2019 